\title{
Coronary CT angiography in the field of interventional cardiology
}

\author{
Mladen Jukić ${ }^{*}$, \\ Ladislav Pavić', \\ Petar Medaković', \\ Dražen Lovrić', \\ Ivan Bitunjac ${ }^{2}$ \\ 'Sunce Clinic, Zagreb, \\ Croatia \\ ${ }^{2}$ General Hospital "Dr. Josip \\ Benčević", Slavonski Brod, \\ Croatia
}

RECEIVED:

February 9, 2016

ACCEPTED:

February 20, 2016

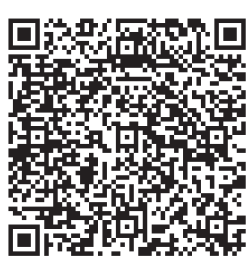

$\square$ Cardiologia Croatica 2016;11(3-4):118.
KEYWORDS: Coronary CT angiography, coronary artery disease, invasive coronary angiography.

CITATION: Cardiol Croat. 2016;11(3-4):118. | DOI: http://dx.doi.org/10.15836/ccar2016.118

*ADDRESS FOR CORRESPONDENCE: Mladen Jukić, Poliklinika Sunce, Trnjanska cesta 108, HR-10000 Zagreb, Croatia. / Phone: +385-1-5497-410 / E-mail: mladen.jukic@sunce.hr

ORCID: Mladen Jukić, http://orcid.org/0000-0002-3927-3888 • Ladislav Pavić, http://orcid.org/0000-0002-8048-998X Petar Medaković, http://orcid.org/0000-0002-7173-8286 • Dražen Lovrić, http://orcid.org/0000-0003-2702-5710 Ivan Bitunjac, http://orcid.org/0000-0002-4396-6628

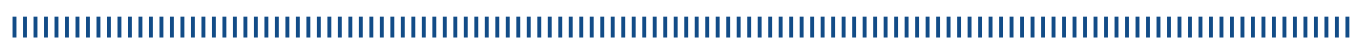

In recent years, coronary CT angiography (CCTA) has become a widely adopted technique, not only due to its high diagnostic accuracy, but also to the fact that CCTA provides a comprehensive evaluation of the total (obstructive and non-obstructive) coronary atherosclerotic burden ${ }^{1}$

We introduced CCTA in our institution (and country as well) in 2007, and since then have scanned over 7000 patients, mostly for suspected coronary artery disease (CAD), accumulating reasonable experience in this respect. In our own study of 792 patients, conducted during 2009, we tried to systematically evaluate how CCTA influenced the management and treatment of our patients with stable CAD 2 . Among other results, we showed that CCTA was able to safely replace diagnostic invasive coronary angiography (ICA) in the majority (77.2\%) of patients, no matter the pre-test risk stratification. Further on, findings on CCTA significantly influenced the choice and aggressiveness of medical therapy. Almost all patients had therapy introduced earlier, as based on pre-test risk stratification, but it was still upgraded in $35.6 \%$ of patients following CCTA, probably demonstrating the importance of CAD burden visualization in clinical decision making.

More recently, a considerable body of evidence has showed what we believe to be the superiority of CCTA in prognostic evaluation of coronary artery atherosclerosis in comparison with other invasive and non-invasive modalities. Further on, due to superb presentation of plaque position, length and composition, CCTA can improve planning of coronary artery interventions. CCTA can also be very valuable in structural heart interventions / surgery, with transcatheter aortic valve implantation being one of its most successful examples. According to current guidelines CCTA is now an established, noninvasive technique that can rapidly exclude obstructive CAD and identify patients who can be safely discharged from the emergency department

Based on our experience ${ }^{2}$, and published data, we believe that CCTA can have an important role in a new management model of patients with suspected CAD that is more patient-centered and pro-active. Not only as a gatekeeper ICA, which presents its by now established role, but also in all other above mentioned aspects CCTA can provide valuable additional information.

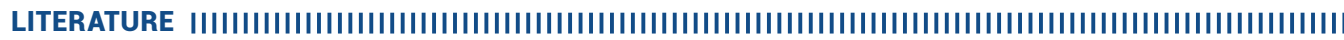

1. de Araújo Gonçalves P, Campos CA, Serruys PW, Garcia-Garcia HM. Computed tomography angiography for the interventional cardiologist. Eur Heart J Cardiovasc Imaging. 2014;15(8):842-54. DoI: http://dx.doi.org/10.1093/ehjci/jeu053

2. Jukić M, Pavić L, Čerkez Habek J, Medaković P, Delić Brkljačić D, Brkljačić B. Influence of coronary computed tomography-angiography on patient management. Croat Med J. 2012;53:4-10. DOI: http://dx.doi.org/10.3325/cmj.2012.53.4 